STRUCTURAL BIOLOGY COMMUNICATIONS

ISSN 2053-230X

Received 10 April 2019

Accepted 24 June 2019

Edited by M. J. Romao, Universidade Nova de Lisboa, Portugal

Keywords: haemoglobin; Gadus morhua; Atlantic cod.

PDB reference: cod haemoglobin, 6hit

Supporting information: this article has supporting information at journals.iucr.org/f

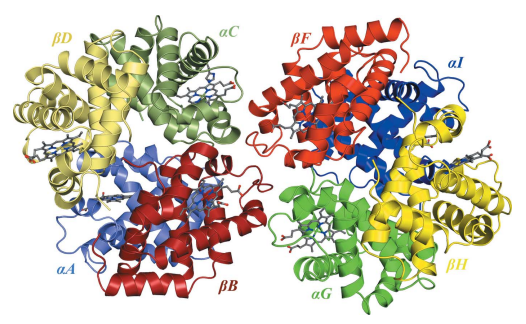

OPEN $\odot$ ACCESS

\section{The crystal structure of haemoglobin from Atlantic cod}

\author{
Ronny Helland, ${ }^{a *}$ Eva Katrin Bjørkeng, ${ }^{a}$ Ulli Rothweiler, ${ }^{a}$ Magne Olav Sydnes ${ }^{b}$ and \\ Daniela Maria Pampanin ${ }^{\mathrm{b}, \mathrm{c} *}$
}

\begin{abstract}
${ }^{a}$ NorStruct, Department of Chemistry, Faculty of Science and Technology, UiT - The Arctic University of Norway, NO-9037 Tromsø, Norway, ${ }^{\mathbf{b}}$ Department of Chemistry, Bioscience and Environmental Engineering, University of Stavanger, Faculty of Science and Technology, NO-4036 Stavanger, Norway, and ${ }^{\mathrm{N}}$ NORCE AS, Prof. Olav Hanssensvei 15, NO-4021 Stavanger, Norway. ${ }^{*}$ Correspondence e-mail: ronny.helland@uit.no, daniela.m.pampanin@uis.no
\end{abstract}

The crystal structure of haemoglobin from Atlantic cod has been solved to $2.54 \AA$ resolution. The structure consists of two tetramers in the crystallographic asymmetric unit. The structure of haemoglobin obtained from one individual cod suggests polymorphism in the tetrameric assembly.

\section{Introduction}

Increasing the knowledge of how Atlantic cod (Gadus morhua) is affected by chemicals that contaminate the aquatic environment has been a longstanding effort (Karlsen et al., 2011; Pampanin, 2017; Pampanin et al., 2014, 2016; Pampanin \& Sydnes, 2013; Sundt et al., 2012). Environmental pollutants such as polycyclic aromatic hydrocarbons (PAHs), resulting for example from oil exploration and production operations or accidental oil spills, have received attention from researchers since the 1970s owing to their carcinogenic potential (United States Environmental Protection Agency, 2009). However, only in recent years, with the development of new and more sensitive analytical methods, has it become possible to obtain a deeper understanding of the adverse effects and the mode of action of these contaminants (Beyer et al., 2011; Enerstvedt, Sydnes, Larssen et al., 2018; Enerstvedt et al., 2017; Enerstvedt, Sydnes \& Pampanin, 2018; Karlsen et al., 2011).

In fish, PAHs are metabolized in vivo in order to make them more water-soluble, thus facilitating excretion (Pampanin \& Sydnes, 2013). However, this process generates products that can potentially be more toxic than the parent compounds. Some of them can react with molecules such as DNA and proteins and form adducts, producing genotoxic effects or impairment of metabolism (Pampanin et al., 2017). In humans, adducts of haemoglobin have been studied substantially as an important method of evaluating individual health conditions (Stedingk et al., 2012). As an example, PAHs derived from tobacco smoking have been found to make adducts with particular amino acids in haemoglobin (Phillips \& Venitt, 2012). It is reasonable to believe that this would also be the case for Atlantic cod, and this hypothesis is strengthened by the fact that PAH adducts with other blood proteins have been identified in this fish species (Enerstvedt et al., 2017; Enerstvedt, Sydnes \& Pampanin, 2018). The potential use of haemoglobin adducts as potential biomarkers of PAH exposure in Atlantic cod is under investigation in our research 
Table 1

Crystallization conditions for cod haemoglobin.

\begin{tabular}{ll}
\hline Method & Hanging drop \\
Plate type & 24-well, Hampton Research \\
Temperature $(\mathrm{K})$ & 298 \\
Protein concentration $\left(\mathrm{mg} \mathrm{ml}^{-1}\right)$ & 8 \\
Composition of reservoir solution & $0.1 \mathrm{M}$ Bicine $\mathrm{pH} \mathrm{8.5,} \mathrm{12 \%} \mathrm{PEG} \mathrm{5K} \mathrm{MME}$ \\
Volume and ratio of drop & $0.25 \mu \mathrm{l}+0.25 \mu \mathrm{l}$ \\
Volume of reservoir $(\mu \mathrm{l})$ & 500 \\
\hline
\end{tabular}

group. Therefore, in order to study the structural effects that a PAH adduct would have on haemoglobin, the structure of this protein has to be defined in the presence and the absence of the adduct. Firstly, however, pure haemoglobin needs to be obtained. The full genome of Atlantic cod has been sequenced (Star et al., 2011), and about 70 isoforms of haemoglobin have been proposed by the EST translation of the genome. However, sequence similarity within the $\alpha$ and $\beta$ forms of cod haemoglobin is high, simplifying the structure-identification research challenge. Here, isolation of the dominant isoform of haemoglobin from Atlantic cod caught in southwest Norway is reported and its X-ray crystal structure is presented.

\section{Materials and methods}

\subsection{Macromolecule production}

2.1.1. Blood sampling. An individual Atlantic cod caught in Idsefjord, Stavanger, Norway using baited traps was kept in a 10001 glass-fibre tank with a continuous-flow system (water temperature $8^{\circ} \mathrm{C}$, salinity 33\%o, light/darkness $8 / 16 \mathrm{~h}$, water flow 7-9 $1 \mathrm{~min}^{-1}$ ). Haemoglobin was obtained from the fish by extracting blood samples over a period of four weeks (total amount $10 \mathrm{ml}$ ). Heparin was used as an anticoagulant and the blood samples were centrifuged for $5 \mathrm{~min}$ at $2000 \mathrm{~g}$ and $4^{\circ} \mathrm{C}$. Plasma fractions were removed and the remaining red blood cell (RBC) fractions were kept at $-80^{\circ} \mathrm{C}$ until further analysis.

2.1.2. Purification. A blood sample of about $500 \mu \mathrm{l}$ from the cod was thawed and lysed by incubating the sample overnight at $4^{\circ} \mathrm{C}$ in $8 \mathrm{ml} 4 \mathrm{~m} M$ Tris $\mathrm{pH} 7.5,10 \mathrm{~m} M \mathrm{NaCl}, 2 \mu \mathrm{l}$ DNaseI.

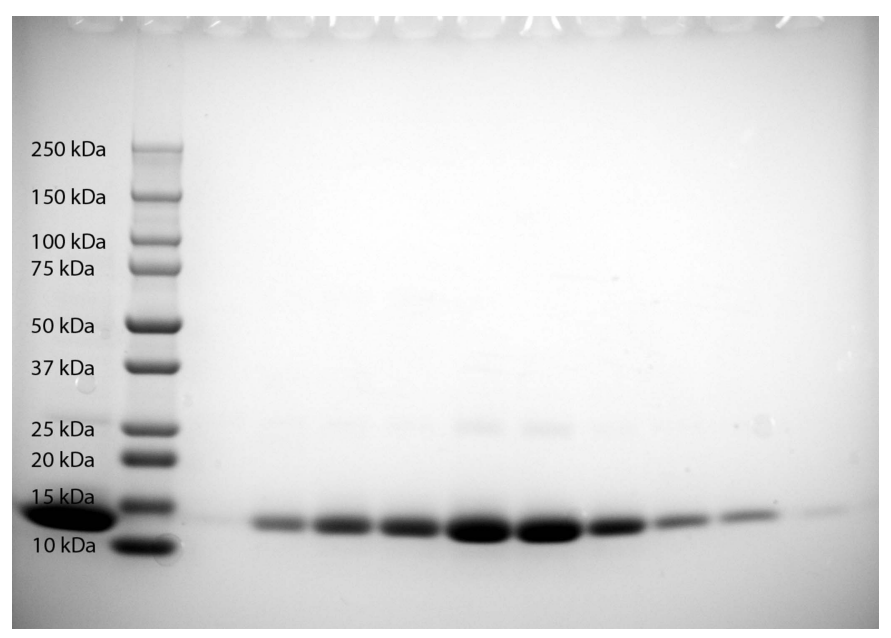

Figure 1

SDS-PAGE illustrating the purity of fractions containing cod haemoglobin.
$2 \mathrm{ml}$ of the lysed sample was diluted to $10 \mathrm{ml}$ using $50 \mathrm{~m} M$ Tris pH 9.5 (buffer $A$ ). Samples were subsequently applied onto a $5 \mathrm{ml}$ HiTrap QHP column (IEX) for anion-exchange chromatography. A washing step using $60 \% 50 \mathrm{mM}$ bis-Tris propane $\mathrm{pH} 5.5$ (buffer $B$ ) was included before eluting the protein using a gradient from $60 \%$ to $100 \%$ buffer $B$ over $60 \mathrm{ml}$. Fractions containing haemoglobin were subjected to sodium dodecyl sulfate-polyacrylamide gel electrophoresis (SDS-PAGE) for assessment of purity (Fig. 1) before being pooled and concentrated to $16 \mathrm{mg} \mathrm{ml}^{-1}$ using $3 \mathrm{~K}$ Amicon Ultra spin filters.

\subsection{Crystallization}

Initial crystallization conditions were screened with a Phoenix crystallization robot (Art Robbins Instruments) using the sitting-drop vapour-diffusion method. A total of 480 inhouse conditions were screened in MRC plates with $60 \mu \mathrm{l}$ reservoir solution per well; drop solutions were prepared by mixing $0.25 \mu \mathrm{l}$ well solution and $0.25 \mu \mathrm{l}$ protein solution at $16 \mathrm{mg} \mathrm{ml}^{-1}$. Further optimization in Hampton Research 24-well hanging-drop plates using $500 \mu$ reservoirs, a protein concentration of $8 \mathrm{mg} \mathrm{ml}^{-1}$ and $1 \mu \mathrm{l}+1 \mu \mathrm{l}$ drops yielded thin needle-shaped and plate-like crystals from 12\% PEG 5K MME, $0.1 M$ Bicine pH 8.5 (Table 1, Fig. 2).

\subsection{Data collection, processing and structure determination}

Data were collected on beamline ID23-1 at the ESRF (Nurizzo et al., 2006). All data were integrated and scaled using XDS (Kabsch, 2010) and AIMLESS (Evans \& Murshudov, 2013; Winn et al., 2011). Data-collection statistics are listed in Table 2. The structure was solved by molecular replacement in Phaser (McCoy et al., 2007) and subsequent autobuilding using RESOLVE in PHENIX (Adams et al., 2010; Afonine et al., 2012; Grosse-Kunstleve \& Adams, 2003; Moriarty et al., 2009; Terwilliger, 2004; Terwilliger et al., 2008, 2009; Zwart, 2005).

The template for molecular replacement was generated by homology modelling using the structure of haemoglobin from yellow perch (PDB entry 1xq5; Center for Eukaryotic

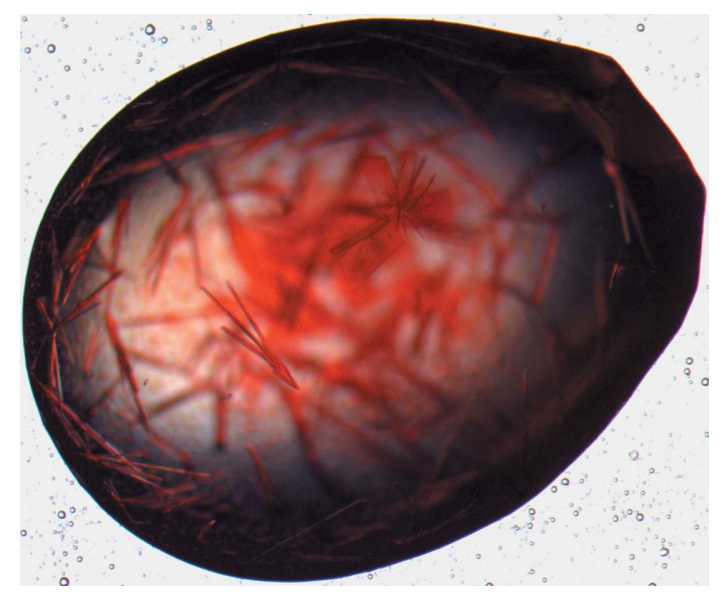

Figure 2

Cod haemoglobin crystals. 
Table 2

Data-collection and processing statistics.

Values in parentheses are for the outer shell.

\begin{tabular}{ll}
\hline Diffraction source & ID23-1, ESRF \\
Wavelength $(\AA)$ & 0.9840 \\
Temperature $(\mathrm{K})$ & 100 \\
Detector & PILATUS 6M-F \\
Crystal-to-detector distance $(\mathrm{mm})$ & 498.92 \\
Rotation range per image $\left(^{\circ}\right)$ & 0.15 \\
Total rotation range $\left(^{\circ}\right)$ & 120 \\
Space group & $P 2{ }_{1} 2{ }_{1} 2{ }_{1}$ \\
$a, b, c(\AA)$ & $62.69,103.26,199.35$ \\
$\alpha, \beta, \gamma\left({ }^{\circ}\right)$ & $90,90,90$ \\
Mosaicity $\left(^{\circ}\right)$ & 0.2 \\
Resolution range $(\AA)$ & $50-2.54(2.63-2.54)$ \\
Total No. of reflections & $197786(18871)$ \\
No. of unique reflections & $45021(4302)$ \\
Completeness $(\%)$ & $98.8(97.3)$ \\
Multiplicity & $4.4(4.4)$ \\
$I / \sigma(I) \dagger$ & $7.2(0.9)$ \\
$\langle I / \sigma(I)\rangle$ & $10.6(1.7)$ \\
$R_{\text {r.i.m. }}(\%)$ & $10.0(89.4)$ \\
$R_{\text {merge }}(\%)$ & $7.9(71.6)$ \\
$C C_{1 / 2}$ & $0.997(0.597)$ \\
Overall $B$ factor from Wilson plot $\left(\AA^{2}\right)$ & 49.2 \\
\hline
\end{tabular}

$\dagger I / \sigma(I)$ in the outer shell falls below 2.0 at $2.8 \AA$.

Structural Genomics, unpublished work) and BLAST sequences for the $\alpha$ and $\beta$ chains of cod haemoglobin (GenBank codes ABV21458.1 and ACV69847.1, respectively). Homology models of the $\alpha$ and $\beta$ chains were generated using the Schrödinger software suite (https:// www.schrodinger.com/) and were assembled into a tetramer similar to PDB entry 1xq5.

Inspection of electron-density maps was carried out in Coot (Emsley et al., 2010), followed by restrained positional refinement in REFMAC (Murshudov et al., 2011). Refinement statistics are listed in Table 3. To confirm the polypeptide sequence, cod haemoglobin was subjected to in-solution digestion and subsequent mass-spectrometric analysis.

The structure of cod haemoglobin has been deposited in the Protein Data Bank as entry 6hit.

\section{Results and discussion}

A new purification protocol was established by modifying the method described previously by Delatorre et al. (2000). The sample was loaded onto an anion-exchange chromatography column at high $\mathrm{pH}$ and was eluted by a gradual reduction of the $\mathrm{pH}$. Cod haemoglobin at $16 \mathrm{mg} \mathrm{ml}^{-1}$ with a purity sufficient for crystallographic studies was obtained (Fig. 1).

Thin needle-shaped and plate-like crystals grew in bundles from 12\% PEG 5K MME, $0.1 M$ Bicine pH 8.5 (Fig. 2). Optimization of the crystallization conditions, in an attempt to obtain larger single crystals, proved to be difficult. The optimization included a reduction in the protein and/or precipitant concentration, seeding and the use of additives. Single crystals were difficult to isolate and data could often not be processed because of multiple crystals or lattices. The best data were collected to $2.5 \AA$ resolution from a crystal of approximately $0.3 \times 0.05 \times 0.05 \mathrm{~mm}$ in size on beamline ID23-1 at the ESRF.
Table 3

Structure-solution and refinement statistics.

Values in parentheses are for the outer shell.

\begin{tabular}{ll}
\hline Resolution range $(\AA)$ & $50-2.54(2.56-2.54)$ \\
Completeness (\%) & $98.3(96.3)$ \\
$\sigma$ Cutoff & None \\
No. of reflections, working set & $40577(3047)$ \\
No. of reflections, test set & $2191(142)$ \\
Final $R_{\text {cryst }}(\%)$ & $23.23(32.7)$ \\
Final $R_{\text {free }}(\%)$ & $30.13(36.2)$ \\
Cruickshank DPI & 0.6 \\
No. of non-H atoms & \\
$\quad$ Protein & 8582 \\
$\quad$ Ligand & 240 \\
$\quad$ Solvent & 0 \\
R.m.s. deviations from ideal values & \\
$\quad$ Bond lengths $(\AA)$ & 0.013 \\
$\quad$ Angles $\left({ }^{\circ}\right)$ & 1.607 \\
Average $B$ factors $\left(\AA^{2}\right)$ & \\
Protein & 59.8 \\
Ligand & 57.9 \\
Ramachandran plot & \\
$\quad$ Most favoured $(\%)$ & 90.7 \\
$\quad$ Allowed $(\%)$ & 8.4 \\
Generously allowed $(\%)$ & 0.6 \\
Disallowed $(\%)$ & 0.3 \\
\hline
\end{tabular}

The crystal belonged to space group $P 2{ }_{1} 2{ }_{1}{ }_{1}$, with unit-cell parameters $a=62, b=103, c=199 \AA$. Data-collection statistics are listed in Table 1.

The crystal volume-to-molecular weight ratio suggested the presence of eight haemoglobin molecules in the asymmetric unit. A homology model of tetrameric cod haemoglobin (made for pre-crystallographic studies) was used as a template for structure determination using molecular replacement. Phaser (McCoy et al., 2007) was able to identify two tetramers in the asymmetric unit [Fig. 3(a)]. The solution was confirmed by running Phaser using PDB entry 1xq5 as the template. Autobuilding was carried out using the 'simulated annealing' option with the tetrameric homology model as the starting model instead of PDB entry 1xq5. The model was chosen to avoid fragmentation of the polypeptide sequences during autobuilding and to maintain the intrinsic order of the $\alpha$ and $\beta$ chains, which are structurally very similar. The homologybased sequences were edited to correspond to the sequences obtained by mass spectrometry. Manual refitting of electrondensity maps and subsequent restrained positional refinement, including isotropic $B$-factor refinement, resulted in a final structure with $R_{\text {work }}=23.23 \%$ and $R_{\text {free }}=30.13 \%$.

The cod haemoglobin shares $64 \%$ and $74 \%$ sequence identity with the yellow perch haemoglobin (PDB entry 1xq5) $\alpha$ and $\beta$ chains, respectively, and the yellow perch tetramer superimposes on that of cod haemoglobin with r.m.s.d.s of 1.02 and $0.96 \AA$ for the $A B C D$ and $E F G H$ tetramers, respectively [Fig. 3(b)]. The two cod haemoglobin tetramers superimpose on each other with an r.m.s.d. of $0.51 \AA$. The r.m.s.d.s between individual monomers are of the order of $0.38-0.78$ and $0.46-$ 1.12 for the $\alpha$ and $\beta$ chains, respectively. Differences in conformation are primarily located in the loop between residues 45-60 and the C-terminal loops. Differences in conformation are observed in the same regions between the cod and perch haemoglobins. 
The electron density is generally well defined for internal residues, but can be weaker for surface-exposed side chains. The quality of the electron density differs between polypeptide chains that are identical (i.e. chains $A, C, E$ and $G$ and chains $B, D, F$ and $H$ ). In places where the electron density is weak, the conformation of the peptide is based on the conformation of other chains in which the electron density is better defined. This could be the explanation for the relatively large difference between $R$ and $R_{\text {free }}$.

Eight heme groups could be located in the electron density. The residues forming heme-binding sites are reasonably well defined, as are the heme propionate groups. The heme iron appears to be pentacoordinated in all subunits. Weak difference density in the vicinity of the iron in some of the heme groups may suggest a coordinated water or hydroxyl molecule at the sixth coordinating position, as observed in haemoglobin from, for example, perch (PDB entry 3bj3; Aranda et al., 2009). However, additional studies are needed to confirm this. The side chains of the histidines in the $\alpha$ and $\beta$ units have conformations similar to that observed for perch haemoglobin, with distances of about 4.0-4.4 and 2.1-2.3 $\AA$ between the histidinyl $\mathrm{N}^{\varepsilon 2}$ atom and $\mathrm{Fe}$ for $\alpha$-chain residues His60 and His89, respectively, and 4 and 2.1-2.4 $\AA$ for $\beta$-chain residues His64 and His93, respectively. Haemoglobins from cold- adapted species have been found to follow distinct autooxidation patterns (Vitagliano et al., 2004, 2008; Aranda et al., 2009). The small differences in the distances and the amount of difference density observed close to the heme iron may suggest different states of autooxidation (Fig. 4). The electron density suggests that the tetramers may consist of different isoforms of the $\alpha$ and $\beta$ subunits. This is not totally unexpected since heterogeneity in fish haemoglobins has been suggested previously (Sick, 1961; Andersen et al., 2009). For example, the electron density of $\alpha$-unit chain $A$, but not chain $C$, resembles the sequence (ACJ66341) reported by Andersen et al. (2009). However, refinement using this sequence did not improve the refinement statistics, and the $R$ and $R_{\text {free }}$ values were about $5 \%$ higher. Similarly, the $\beta$-unit chain $D$ (and $H$ ) appears to have Ala at position 68 instead of Ile or Val which are usually found at this position. The cod haemoglobin structure presented in this work appears to have Ala at position 63 and Leu at position 56 in the $\beta$ chains, instead of Lys or Met, which are more common in cod sequences. Work by Andersen et al. (2009) suggests that smaller residues in these positions increase the oxygen affinity.

Blood samples were collected from a single individual fish with the aim of avoiding polymorphism owing to genetic variation. Although the resolution of the data is sufficient to
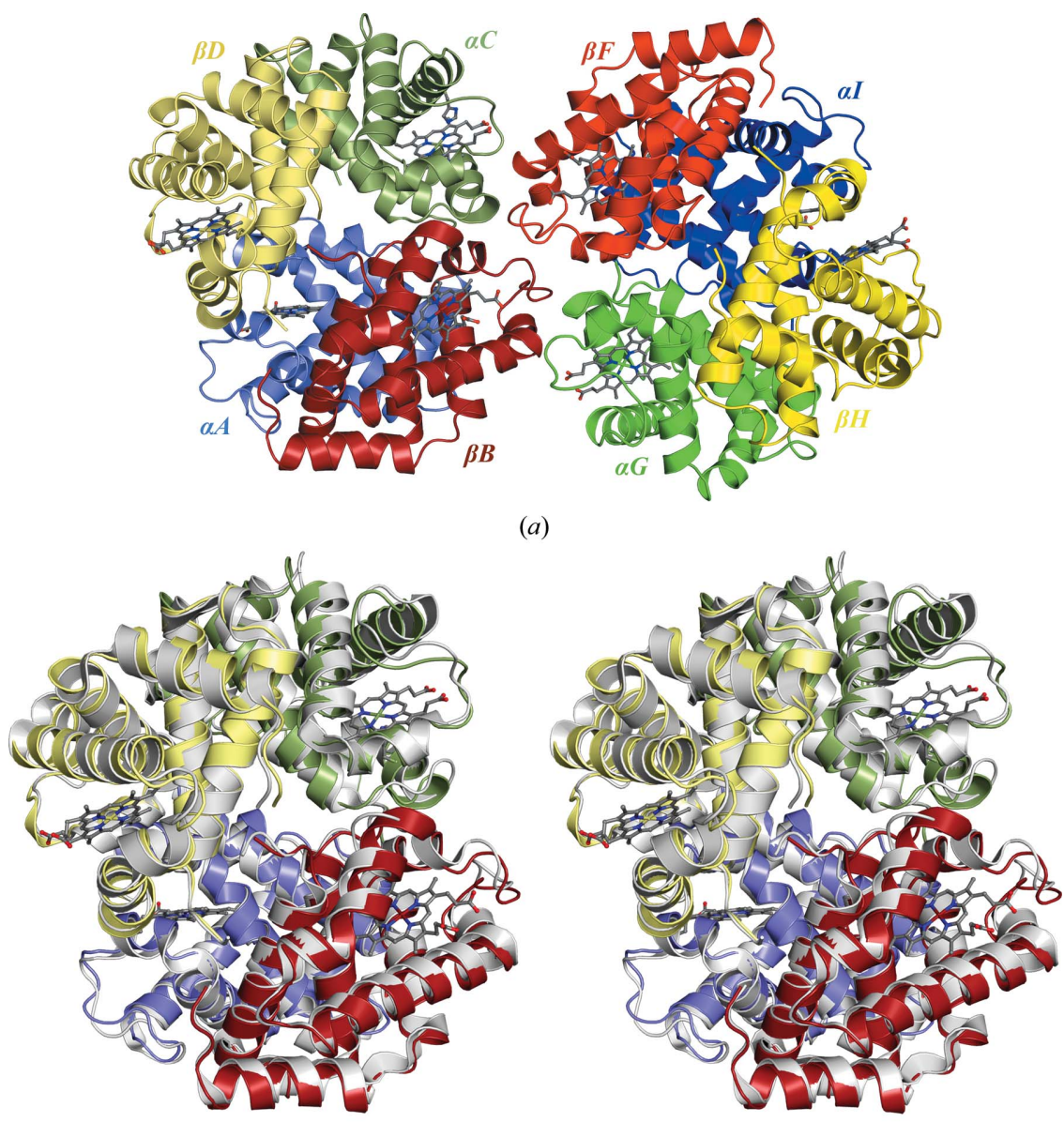

(b)

Figure 3

(a) Ribbon illustration of the two cod haemoglobin tetramers in the crystallographic asymmetric unit. (b) Stereoview showing superimposition of yellow perch haemoglobin (grey) on cod haemoglobin tetramer $A B C D$. 


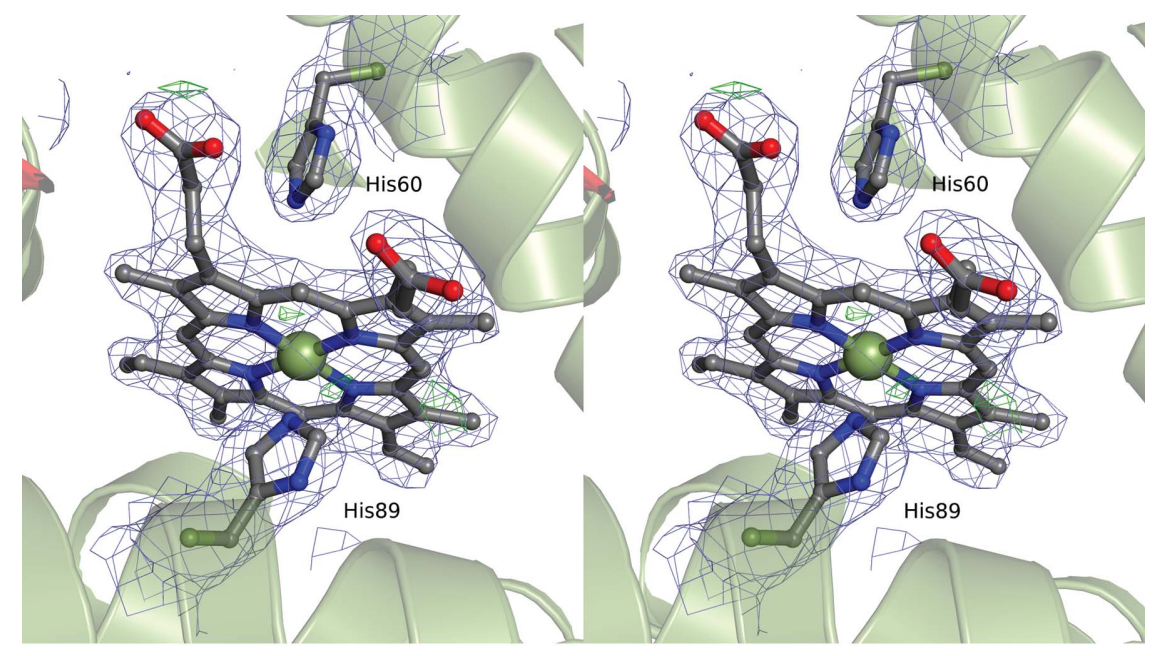

(a)

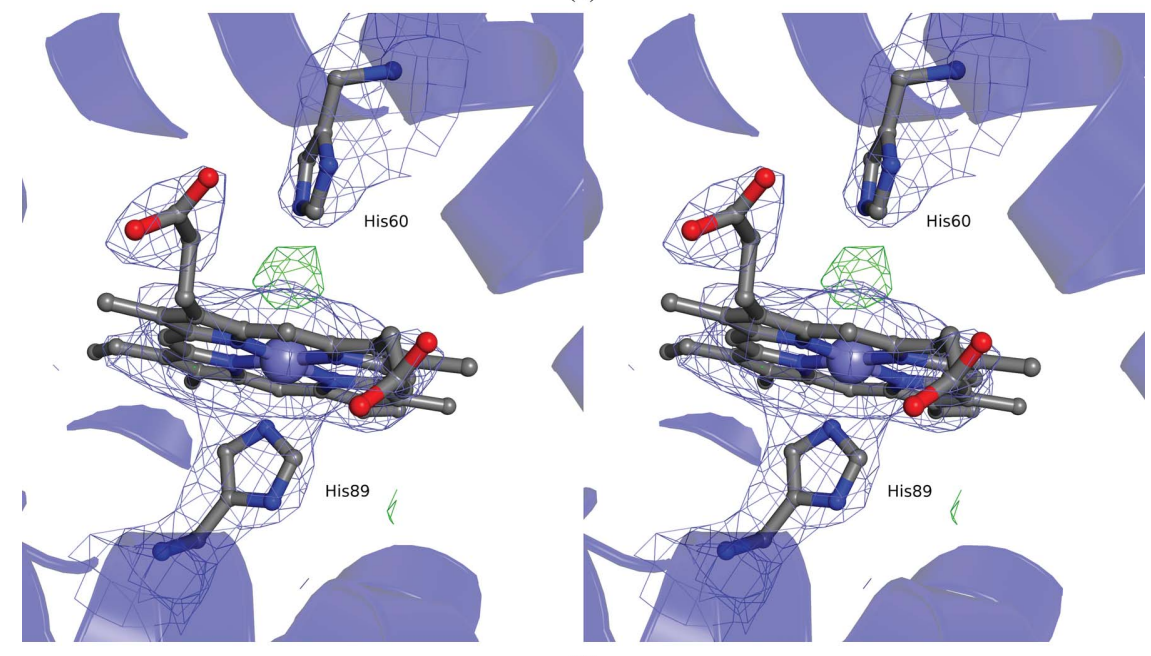

(b)

Figure 4

Stereoview illustrating the electron density for heme $\alpha$-unit chain $C(a)$ and chain $E(b) .2 F_{\mathrm{o}}-F_{\mathrm{c}}$ (blue) and $F_{\mathrm{o}}-F_{\mathrm{c}}$ (green) maps are contoured at $1 \sigma$ and $3 \sigma$, respectively.

trace most of the polypeptide chains, it is not sufficient to specifically identify particular amino-acid residues. The difference electron-density maps suggest polymorphism in both the $\alpha$ and the $\beta$ chains. However, the majority of the polypeptide chains could be traced with adequate certainty and can thus serve as a starting point for further analysis of adduct formation in Atlantic cod haemoglobin exposed to $\mathrm{PAH}$ contamination.

\section{Acknowledgements}

Provision of beamtime at the European Synchrotron Radiation Facility (ESRF) and the BESSY II electron-storage ring operated by the Helmholtz-Zentrum, Berlin is greatly acknowledged. The authors would also like to thank Karianne S. Enerstvedt for help with blood sampling. The Proteomics Platform at UiT - The Arctic University of Norway is thanked for help with MS analysis.

\section{Funding information}

The Research Council of Norway programs PETROMAKS 2 (project No. 229153) and Syncnøyt (project No. 247732) are gratefully acknowledged for financial support.

\section{References}

Adams, P. D., Afonine, P. V., Bunkóczi, G., Chen, V. B., Davis, I. W., Echols, N., Headd, J. J., Hung, L.-W., Kapral, G. J., GrosseKunstleve, R. W., McCoy, A. J., Moriarty, N. W., Oeffner, R., Read, R. J., Richardson, D. C., Richardson, J. S., Terwilliger, T. C. \& Zwart, P. H. (2010). Acta Cryst. D66, 213-221.

Afonine, P. V., Grosse-Kunstleve, R. W., Echols, N., Headd, J. J., Moriarty, N. W., Mustyakimov, M., Terwilliger, T. C., Urzhumtsev, A., Zwart, P. H. \& Adams, P. D. (2012). Acta Cryst. D68, 352-367. Andersen, Ø., Wetten, O. F., De Rosa, M. C., Andre, C., Carelli Alinovi, C., Colafranceschi, M., Brix, O. \& Colosimo, A. (2009). Proc. R. Soc. Lond. B Biol. Sci. 276, 833-841.

Aranda, R. IV, Cai, H., Worley, C. E., Levin, E. J., Li, R., Olson, J. S., Phillips, G. N. Jr \& Richards, M. P. (2009). Proteins, 75, 217-230.

Beyer, J., Sundt, R. C., Sanni, S., Sydnes, M. O. \& Jonsson, G. (2011). J. Toxicol. Environ. Health A, 74, 569-581. 
Delatorre, P., Delamano, M., Fadel, V., Honda, R. T., Smarra, A. L. S., Canduri, F., Olivieri, J. R., Bonilla-Rodriquez, G. O. \& de Azevedo, W. F. (2000). Eclet. Quim. 25, 147-159.

Emsley, P., Lohkamp, B., Scott, W. G. \& Cowtan, K. (2010). Acta Cryst. D66, 486-501.

Enerstvedt, K. S., Sydnes, M. O., Larssen, E. \& Pampanin, D. M. (2018). Chemosphere, 200, 67-79.

Enerstvedt, K. S., Sydnes, M. O. \& Pampanin, D. M. (2017). Chemosphere, 183, 294-304.

Enerstvedt, K. S., Sydnes, M. O. \& Pampanin, D. M. (2018). Mar. Environ. Res. 138, 46-54.

Evans, P. R. \& Murshudov, G. N. (2013). Acta Cryst. D69, 12041214.

Grosse-Kunstleve, R. W. \& Adams, P. D. (2003). Acta Cryst. D59, 1966-1973.

Kabsch, W. (2010). Acta Cryst. D66, 125-132.

Karlsen, O. A., Bjørneklett, S., Berg, K., Brattås, M., Bohne-Kjersem, A., Grøsvik, B. E. \& Goks $\varnothing y r$, A. (2011). J. Toxicol. Environ. Health A, 74, 494-507.

McCoy, A. J., Grosse-Kunstleve, R. W., Adams, P. D., Winn, M. D., Storoni, L. C. \& Read, R. J. (2007). J. Appl. Cryst. 40, 658674.

Moriarty, N. W., Grosse-Kunstleve, R. W. \& Adams, P. D. (2009). Acta Cryst. D65, 1074-1080.

Murshudov, G. N., Skubák, P., Lebedev, A. A., Pannu, N. S., Steiner, R. A., Nicholls, R. A., Winn, M. D., Long, F. \& Vagin, A. A. (2011). Acta Cryst. D67, 355-367.

Nurizzo, D., Mairs, T., Guijarro, M., Rey, V., Meyer, J., Fajardo, P., Chavanne, J., Biasci, J.-C., McSweeney, S. \& Mitchell, E. (2006). J. Synchrotron Rad. 13, 227-238.

Pampanin, D. M. (2017). Petrogenic Polycyclic Aromatic Hydrocarbons in the Aquatic Environment: Analysis, Synthesis, Toxicity and Environmental Impact, edited by D. M. Pampanin \& M. O. Sydnes, pp. 18-49. Sharjah: Bentham Science Publishers.

Pampanin, D. M., Brooks, S. J., Grøsvik, B. E., Le Goff, J., Meier, S. \& Sydnes, M. O. (2017). Mar. Environ. Res. 125, 49-62.

Pampanin, D. M., Larssen, E., Øysaed, K. B., Sundt, R. C. \& Sydnes, M. O. (2014). Mar. Environ. Res. 101, 161-168.

Pampanin, D. M., Le Goff, J., Skogland, K., Marcucci, C. R., Øysaed, K. B., Lorentzen, M., Jørgensen, K. B. \& Sydnes, M. O. (2016). J. Toxicol. Environ. Health A, 79, 633-646.
Pampanin, D. M. \& Sydnes, M. O. (2013). Hydrocarbon, edited by V. Kutcherov \& A. Kolesnikov, pp. 83-118. Rijeka: InTech.

Phillips, D. H. \& Venitt, S. (2012). Int. J. Cancer, 131, 2733-2753.

Sick, K. (1961). Nature (London), 192, 894-896.

Star, B., Nederbragt, A. J., Jentoft, S., Grimholt, U., Malmstrøm, M., Gregers, T. F., Rounge, T. B., Paulsen, J., Solbakken, M. H., Sharma, A., Wetten, O. F., Lanzén, A., Winer, R., Knight, J., Vogel, J. H., Aken, B., Andersen, O., Lagesen, K., Tooming-Klunderud, A., Edvardsen, R. B., Tina, K. G., Espelund, M., Nepal, C., Previti, C., Karlsen, B. O., Moum, T., Skage, M., Berg, P. R., Gjøen, T., Kuhl, H., Thorsen, J., Malde, K., Reinhardt, R., Du, L., Johansen, S. D., Searle, S., Lien, S., Nilsen, F., Jonassen, I., Omholt, S. W., Stenseth, N. C. \& Jakobsen, K. S. (2011). Nature (London), 477, 207-210.

Stedingk, H., Osterman-Golkar, S. \& Törnqvist, M. (2012). Issues in Toxicology, Biomarkers and Human Biomonitoring, edited by L. Knudsen \& D. F. Merlo, pp. 1-22. Cambridge: Royal Society of Chemistry.

Sundt, R. C., Ruus, A., Jonsson, H., Skarphéðinsdóttir, H., Meier, S., Grung, M., Beyer, J. \& Pampanin, D. M. (2012). Mar. Pollut. Bull. 64, 144-152.

Terwilliger, T. C. (2004). Acta Cryst. D60, 2144-2149.

Terwilliger, T. C., Adams, P. D., Read, R. J., McCoy, A. J., Moriarty, N. W., Grosse-Kunstleve, R. W., Afonine, P. V., Zwart, P. H. \& Hung, L.-W. (2009). Acta Cryst. D65, 582-601.

Terwilliger, T. C., Grosse-Kunstleve, R. W., Afonine, P. V., Moriarty, N. W., Adams, P. D., Read, R. J., Zwart, P. H. \& Hung, L.-W. (2008). Acta Cryst. D64, 515-524.

United States Environmental Protection Agency (2009). Polycyclic Aromatic Hydrocarbons (PAHs). https://www.epa.gov/sites/ production/files/2014-03/documents/pahs_factsheet_cdc_2013.pdf.

Vitagliano, L., Bonomi, G., Riccio, A., di Prisco, G., Smulevich, G. \& Mazzarella, L. (2004). Eur. J. Biochem. 271, 1651-1659.

Vitagliano, L., Vergara, A., Bonomi, G., Merlino, A., Verde, C., di Prisco, G., Howes, B. D., Smulevich, G. \& Mazzarella, L. (2008). J. Am. Chem. Soc. 130, 10527-10535.

Winn, M. D., Ballard, C. C., Cowtan, K. D., Dodson, E. J., Emsley, P., Evans, P. R., Keegan, R. M., Krissinel, E. B., Leslie, A. G. W., McCoy, A., McNicholas, S. J., Murshudov, G. N., Pannu, N. S., Potterton, E. A., Powell, H. R., Read, R. J., Vagin, A. \& Wilson, K. S. (2011). Acta Cryst. D67, 235-242.

Zwart, P. H. (2005). Acta Cryst. D61, 1437-1448. 